\title{
Lethal and sublethal effects, and incomplete clearance of ingested imidacloprid in honey bees (Apis mellifera)
}

\author{
Francisco Sánchez-Bayo $^{1} \cdot$ Luc Belzunces $^{2} \cdot$ Jean-Marc Bonmatin $^{3}$
}

Accepted: 5 August 2017

(C) Springer Science+Business Media, LLC 2017

\begin{abstract}
A previous study claimed a differential behavioural resilience between spring or summer honey bees (Apis mellifera) and bumble bees (Bombus terrestris) after exposure to syrup contaminated with $125 \mu \mathrm{g} \mathrm{L}{ }^{-1}$ imidacloprid for 8 days. The authors of that study based their assertion on the lack of body residues and toxic effects in honey bees, whereas bumble bees showed body residues of imidacloprid and impaired locomotion during the exposure. We have reproduced their experiment using winter honey bees subject to the same protocol. After exposure to syrup contaminated with $125 \mu \mathrm{g} \mathrm{L}{ }^{-1}$ imidacloprid, honey bees experienced high mortality rates (up to $45 \%$ ), had body residues of imidacloprid in the range $2.7-5.7 \mathrm{ng} \mathrm{g}^{-1}$ and exhibited abnormal behaviours (restless, apathetic, trembling and falling over) that were significantly different from the controls. There was incomplete clearance of the insecticide during the 10-day exposure period. Our results contrast with the findings reported in the previous study for spring or summer honey bees, but are consistent with the results reported for the other bee species.
\end{abstract}

Keywords Neonicotinoids $\cdot$ Pesticides $\cdot$ Bees $\cdot$ Chronic exposure $\cdot$ Residues $\cdot$ Detoxification

$\triangle$ Francisco Sánchez-Bayo

francisco.sanchez-bayo@sydney.edu.au

sanchezbayo@mac.com

1 School of Life and Environmental Sciences, Biomedical building, The University of Sydney, Eveleigh, NSW 2015, Australia

2 INRA, Laboratoire de Toxicologie Environnementale, UR 406 A\&E, Avignon, France

3 Centre National de la Recherche Scientifique (CNRS), Centre de Biophysique Moléculaire, Orléans 45071, France

\section{Introduction}

A former paper by Cresswell et al. (Cresswell et al. 2014) claimed that newly eclosed honey bees (Apis mellifera) are able to clear completely the insecticide imidacloprid ingested in syrup at a concentration of $125 \mu \mathrm{g} \mathrm{L}{ }^{-1}$ (w/v), whereas bumble bees (Bombus terrestris) had small amounts of imidacloprid residues in their bodies ( $2.4 \mathrm{ng}$ per bee) and experienced sublethal effects such as locomotion and feeding impairment. The authors contend that "the greater feeding rate of bumblebees may be the principle cause of their susceptibility rather than a deficiency in detoxification capacity", but in a similar experiment published earlier (Cresswell et al. 2012) they "speculate that honey bees are better pre-adapted than bumble bees to feed on nectars containing synthetic alkaloids, such as imidacloprid, by virtue of their ancestral adaptation to tropical nectars in which natural alkaloids are prevalent."

However, their results do not agree with previous and later research on the toxicity of this neonicotinoid insecticide to bees conducted by either the manufacturers (e.g. Bayer Co.) or independent researchers, which indicate that imidacloprid concentrations in syrup above $20 \mathrm{ng} \mathrm{g}^{-1}$ (ppb) cause a reduction in foraging activity in honey bees (Schmuck et al. 2001), while concentrations above $50 \mathrm{ng}$ $\mathrm{g}^{-1}$ alter the foraging behaviour (Ramirez-Romero et al. 2005; Yang et al. 2008). Some of the latter effects involve changes in the olfactory conditioning of the proboscis extension and learning performance, both of which are about three times more sensitive in summer honey bees than in winter bees, with lowest observable effects of 12 and 48 $\mathrm{ng} \mathrm{g}^{-1}$, respectively (Decourtye et al. 2003). Other authors have found impairment of certain motor functions such as losing postural control and failing to right themselves after a fall, whereas other behaviours (e.g. walking, sitting and 
flying) are not significantly affected at sublethal doses. Such changes in motor function after exposure to imidacloprid are always dose-dependent (Williamson et al. 2014). Besides, feeding activity of honey bees is known to decrease significantly with imidacloprid (Yang et al. 2008) even at concentrations as low as $6 \mathrm{ng} \mathrm{g}^{-1}$ (Colin et al. 2004). These and other sublethal effects have been observed (Desneux et al. 2007) whenever honey bees are treated with this insecticide at dietary concentrations below those used by Cresswell et al. (2014). The same effects have been observed in bumble bees exposed to this insecticide (Laycock et al. 2012; Moffat et al. 2016; Thompson et al. 2015).

An efficient protection of managed pollinators (e.g. honey bees) and wild pollinators (e.g. bumble bees) requires well established knowledge of pesticide effects and metabolism, because the effects could be specific for particular bee species. However, hypothesis on particular mechanisms should be supported by robust evidence, this especially in terms of honey bee type (spring, summer, winter bees) because effects of pesticides can be delayed in time when destocking contaminated food resources. Hence, our purpose here is to reproduce the experiment carried out by Cresswell et al. (2014) but using winter honey bees and extending our observations to additional lethal and sublethal effects. We only tested honey bees, since the results for bumble bees that they reported were consistent with other studies using the same insecticide (Laycock et al. 2012; Moffat et al. 2016). We did not intend, however, to study the metabolic profile of imidacloprid in honey bees in more detail than they did (e.g. no metabolites were analysed), because it is known from previous studies (Suchail et al. 2004a; Suchail et al. 2004b). Equally, this study did not aim at determining the toxic dose-response of imidacloprid on honey bees, as this information is already known (Blacquière et al. 2012; Cresswell 2011).

\section{Experimental methods}

The study was conducted following the same experimental design described by Cresswell et al. (2014), except that we used winter honey bees (Apis mellifera) instead of "newly eclosed worker honey bees". Briefly, two groups of nine cages $(6.5 \times 8.5 \times 10.5 \mathrm{~cm})$ containing ten honey bees each were used for control and treatment, respectively. The treatment group was fed syrup $\left(500 \mathrm{~g} \mathrm{~L}^{-1}\right.$ sucrose) containing $125 \mu \mathrm{g} \mathrm{L}^{-1}$ (w/v; $109 \mu \mathrm{g} \mathrm{kg}^{-1}$ or ppb) imidacloprid (analytical standard, Cluzeau Info-Labo, Sainte Foy la Grande, France) and the control group just untreated syrup. To avoid possible imidacloprid degradation that could occur during the experimental period, aliquots of the sucrose solutions, containing imidacloprid or not (i.e. control), were frozen and stored at $-80^{\circ} \mathrm{C}$. Each day, a fresh feeding solution was provided to the bees by thawing aliquots of sucrose solutions containing or not imidacloprid. The concentrations of imidacloprid in the feeding solution was checked by chemical analyses performed before and after freezing at $-80^{\circ} \mathrm{C}$. The measured concentration of the toxicant was within $10 \%$ (RSD) of the nominal concentration and no change in concentration was observed after freezing during the entire experimental period $(n=4)$. The cages were held in a room at $27 \pm 2{ }^{\circ} \mathrm{C}$ and $70 \%$ relative humidity with a light:night cycle of 12:12 h, and monitored daily for food consumption, mortality and behaviour during 10 days. We replicated the experiment with another two groups of 9 cages setup and monitored exactly the same way but each cage contained 30 honey bees. Nine of those cages were monitored daily for mortality and food consumption, whereas the remaining cages were used for chemical analysis of the bees on days 0, 2, 4, 6, 8 and 10 . Feeders were replaced with fresh syrup every day, with all groups being fed the same syrup prepared on the first day. Feeding consumption was measured daily by weighing the syrup left in the feeders, and was corrected by the number of surviving bees each day.

The experiment started in November 28, 2014 at the facilities of the Laboratory of Environmental Toxicology of INRA (Avignon, France). Therefore, all the bees tested were winter bees, which are less susceptible to imidacloprid than spring or summer bees (Decourtye et al. 2003). The differential susceptibility to toxicants between summer and winter honey bees can be explained by the lack of foraging activity of workers during the winter period, which imposes variable physiological responses. For behavioural studies, 9 different endpoints were considered: locomotor activity/ mobility, which correspond to the ability of walking, climbing and performing short flights; activity, which is distributed into quietness (normal activity compared to control), hyperactivity (rapid and badly controlled movements associated with fast displacements) and apathy (motionless bees); tremors; falls from the walls of the cage; trophallaxis; ventilation (wing beating as bees are static) and feeding behaviour. Video tracking was used for recording the activity of the bees according to the methodology previously published (Colin et al. 2004; Teeters et al. 2012). The bees of each cage were followed for $5 \mathrm{~min}$ five times per day: at 9:30, 10:00, 10:30, 11:00 and $11: 30$.

After the toxicity tests, all bees were immediately frozen and kept at $-24{ }^{\circ} \mathrm{C}$ until chemical analyses of imidacloprid, as the aim of the study was to test whether residues of the parent compound would remain in the bees body during the testing period. Two $\mathrm{g}$ of honey bees (approximately 16-17 bees) were sampled on alternate days, as mentioned above, and analysed for neonicotinoids at the Centre de 
Biophysique Moléculaire (CNRS, France). A blank matrix was provided from a local professional apiary located in a wooded area. The HPLC-MS/MS analytical method was adapted from Bonmatin et al. (Bonmatin et al. 2003). Briefly, after homogenization, extraction was performed with $10 \mathrm{~mL}$ of acetone, with internal standard added (imidacloprid-D4), stirring, recovery and evaporation of the supernatant. Then, the extract was dissolved in acetonitrile and $2 \%$ of acetic acid. A volume of $70 \mu \mathrm{L}$ was mixed with $130 \mu \mathrm{L}$ of mobile phase (water/methanol $65: 35$ and $2 \%$ of acetic acid). Twenty $\mu \mathrm{L}$ were injected in HPLC (C18) with a run time of $9 \mathrm{~min}$. MS/MS analysis was performed in the APCI mode on a triple Quad 5500 mass spectrometer (SCIEX). The method has been fully validated for analysis of imidacloprid, thiamethoxam, clothianidin, acetamiprid and thiacloprid in insects (Drosophila and bees) according to the DG SANCO 12571/2013 criteria for confirmatory methods. More specifically, imidacloprid was detected through its parent ion at $m / z, 256$ and two fragments ions at $\mathrm{m} / \mathrm{z} 209$ and $\mathrm{m} / \mathrm{z} 175$, while the internal standard was used for specificity and quantification criteria using the same fragmentations. Linear coefficients of determination $\left(r^{2}\right)$ were always greater than 0.98 for 5 calibration points in the range $0.5-25 \mathrm{ng} \mathrm{g}^{-1}$. Recovery rates calculated for three levels (each level analysed twice) were always between 80 and $90 \%$. According to the full set of quality criteria, limits of detection ( $0.1 \mathrm{ng} \mathrm{g}^{-1}$ body weight) and quantification $\left(0.5 \mathrm{ng} \mathrm{g}^{-1}\right.$ b.w.) correspond approximately to 12 and $60 \mathrm{pg}$ per bee, respectively.

Statistical comparisons of feeding rates, residue levels and behavioural activities between controls and treatments were performed using paired t-tests. In all cases, $\alpha=0.05$. The apparent half-life of imidacloprid parent compound in honey bees during 10 days of chronic exposure was determined by least-squares linear regression of the imidacloprid levels in bees (log transformed) over the time series. All data analyses were performed using the StatPlus package of Excel software.

\section{Results}

Syrup consumption was not different $(p=0.55$, two-tailed t-test) in the control cages containing either 10 or 30 bees, averaging $42 \pm 17 \mathrm{mg}$ per bee and $38 \pm 17 \mathrm{mg}$ per bee respectively over the 10 days of exposure. Feeding rates in the treated cages were similar, with average consumption of $48 \pm 22 \mathrm{mg}$ per bee and $35 \pm 15 \mathrm{mg}$ per bee in the cages containing 10 and 30 bees, respectively. There was no difference in syrup consumption between the control and treated groups (paired $t$-test: $p=0.57$ for 10 bees per cage; $p=0.70$ for 30 bees per cage).
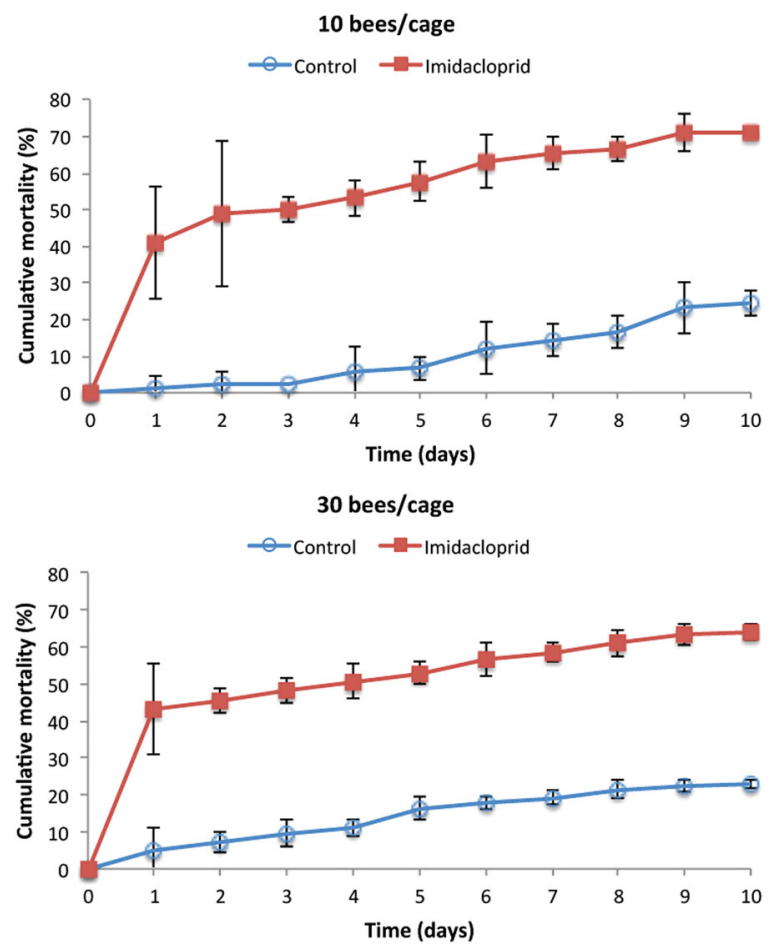

Fig. 1 Cumulative mortality of winter honey bees exposed to imidacloprid during 10 days. Nine cages of either 10 or 30 bees were fed daily a sucrose solution containing $125 \mathrm{\mu g} \mathrm{L}^{-1}$ imidacloprid (squares) or not (circles). Error bars represent standard deviations

\section{Mortality}

The mortality rates of control honey bees after 10 days were $24 \%$ in the cages with 10 bees and $23 \%$ in cages with 30 bees, showing no difference between them. Such rates are considered normal for winter bees (Alkassab and Kirchner 2016; Decourtye et al. 2003). Honey bees that fed on syrup contaminated with imidacloprid showed significantly higher mortality than bees in the controls during the same period: 71 and $61 \%$ for cages with 10 and 30 bees, respectively (Fig. 1). Thus, bee mortality was $41-47 \%$ higher in the treated cages than in the controls after 10 days of exposure.

\section{Residues of imidacloprid in bees}

Bees from the control cages did not have any detectable residues of imidacloprid (i.e. $<0.1 \mathrm{ng} \mathrm{g}^{-1}$ ) at any time during the experiment. By contrast, honey bees from the syrup-treated cages ( 30 bees per cage) had measurable levels of imidacloprid in the range $5.7-2.7 \mathrm{ng} \mathrm{g}^{-1}$ (values not corrected for recovery rates) between days 2 and 10 . No other neonicotinoid (thiamethoxam, clothianidin, acetamiprid and thiacloprid) was found, both in control and treated bees.

Based on the consumption rate, the average daily intake of imidacloprid was $3.8 \pm 2.0 \mathrm{ng}$ per bee, but the cumulative 


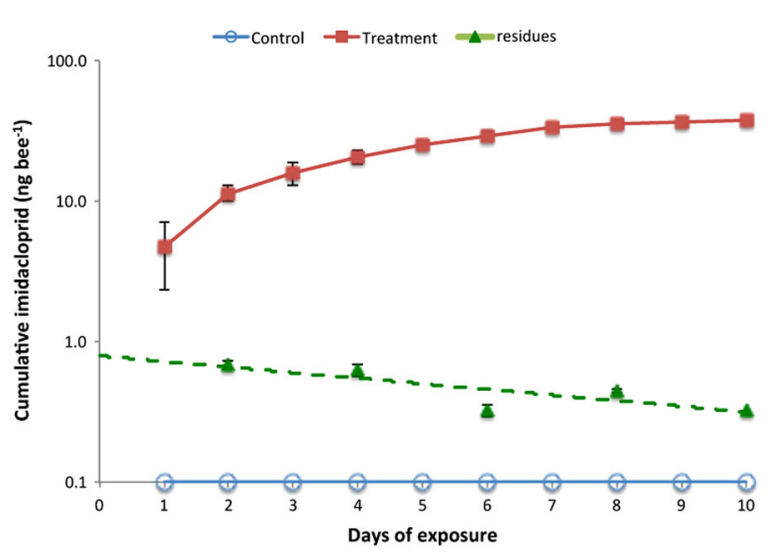

Fig. 2 Exposure profile of honey bees chronically exposed to imidacloprid. The honey bees were exposed to imidacloprid by feeding a sucrose solution containing $125 \mu_{\mathrm{g} \mathrm{L}}^{-1}$ for 10 days. The cumulative intake of imidacloprid (squares) was calculated on the basis of food consumption and imidacloprid concentration. Body residues in the treated bees (ng per bee) were quantified by HPLC-MS/MS (triangles); error bars (see Table 1) are too small to be displayed on a log scale. For controls (circles), imidacloprid intake was null and its residues were always below the limit of detection of $0.1 \mathrm{ng} \mathrm{g}^{-1}$ (i.e. $<12 \mathrm{pg}$ per bee). The stippled line corresponds to a linear regression on the body residues $\left(y=0.726-0.092 \operatorname{LnX}, r^{2}=0.68\right)$, used to estimate the apparent half-life ( 7.6 days) of this insecticide in honey bees

intake of imidacloprid during the 10-day period was curvilinear (Fig. 2) because individual intake was highest on day $1(6.6 \pm 2.4 \mathrm{ng}$ per bee $)$ and lowest on the last day of the experiment $(1.3 \pm 1.2 \mathrm{ng}$ per bee), as previously reported (Colin et al. 2004). Considering the cumulative intake over the experimental period, body residues of imidacloprid on day $2(0.68 \pm 0.04 \mathrm{ng}$ per bee) represent $6 \%$ of the cumulative intake to that day, whereas at the end of the 10-day period the residues $(0.32 \pm 0.01 \mathrm{ng}$ per bee) were $0.9 \%$ of the total intake (Fig. 2). Considering that the metabolism of this insecticide in honey bees is very fast, with an estimated half-life of 4 or $5 \mathrm{~h}$ (Suchail et al. 2004a), at the end of each day $98 \%$ of imidacloprid would have been converted into various metabolites (Suchail et al. 2004b) and only $2 \%$ would remain in the bees' bodies. That is why it is pertinent to compare the body residues of imidacloprid found each day to the intake for the same day. Residues of imidacloprid on day 2 were $10.3 \%$ of the intake for that day alone, whereas on the last day of the experiment the proportion of parent imidacloprid increased to $24.1 \%$ of that day's intake (Table 1). The increase of this relative proportion of imidacloprid suggests a slowdown of its metabolism with exposure time, which had passed un noticed until now, and explains the incomplete clearance of the parent compound at the end of the 10-day exposure period.

It is noteworthy that imidacloprid levels in honey bees have always been above the limit of quantitation $\left(0.5 \mathrm{ng} \mathrm{g}^{-1}\right.$ body weight) during our experiment. The decrease in the
Table 1 Daily intake and residues of imidacloprid in winter honey bees chronically exposed

\begin{tabular}{|c|c|c|c|c|}
\hline Days & $\begin{array}{l}\text { Daily intake } \\
\text { (ng per bee) }\end{array}$ & $\begin{array}{l}\text { Residues } \\
\text { (ng per bee) }\end{array}$ & $\begin{array}{l}\text { Residues } \\
\text { (\% cumulative } \\
\text { intake) }\end{array}$ & $\begin{array}{l}\text { Residues } \\
\text { (\% daily } \\
\text { intake) }\end{array}$ \\
\hline 1 & $4.7 \pm 2.6$ & & & \\
\hline 2 & $6.6 \pm 2.4$ & $0.68 \pm 0.04$ & 6.0 & 10.3 \\
\hline 3 & $4.5 \pm 1.4$ & & & \\
\hline 4 & $4.8 \pm 3.0$ & $0.62 \pm 0.05$ & 3.0 & 13.0 \\
\hline 5 & $4.6 \pm 2.3$ & & & \\
\hline 6 & $4.2 \pm 0.9$ & $0.32 \pm 0.06$ & 1.1 & 7.8 \\
\hline 7 & $3.7 \pm 2.5$ & & & \\
\hline 8 & $2.0 \pm 1.3$ & $0.44 \pm 0.03$ & 1.3 & 21.8 \\
\hline 9 & $1.7 \pm 2.1$ & & & \\
\hline 10 & $1.3 \pm 1.2$ & $0.32 \pm 0.01$ & 0.9 & 24.1 \\
\hline
\end{tabular}

Data represent mean values \pm SD. For daily intake $n=9$, and for residues in bees $n=3$. The percentage of residues was calculated from the residues at given days and (i) the cumulative imidacloprid intake until the day (\% cumulative intake); or (ii) the daily intake of imidacloprid on a given day, on the assumption that the majority $(\sim 98 \%)$ of the previous intake had been metabolised

parent imidacloprid level during this period enabled estimation of a pseudo-apparent half-life of 7.6 days in bees that consumed daily contaminated syrup at $125 \mu \mathrm{g} \mathrm{L}^{-1}$. This contrasts with previously reported half-lives for this insecticide of 4 or $5 \mathrm{~h}$ after a single exposure (Suchail et al. 2004a). Our estimated half-life results from concomitant detoxification processes and chronic intake, neither of which is constant over time, not only because honey bees did not consume contaminated food regularly but also because detoxification efficiency is dependent on the internal amounts of the parent insecticide and its metabolites.

\section{Behavioural effects}

Nine different behaviours were monitored daily in the cages containing 10 bees: locomotor activity or mobility, quietness, hyperactivity, apathy, tremors, falls from the walls of the cage, trophillaxis, ventilation and feeding. Four of these behaviours showed significant differences $(p<0.05$, paired ttest) between control and treated bees: honey bees were more often restless, exhibited trembling, were apathetic and often fell from the walls when exposed to imidacloprid (Fig. 3). It is noteworthy that these differences generally appeared after 1 day of chronic exposure, and changes in behaviours were not constant or related to time. For instance, the four behaviours described above were more strongly affected on days 4 and 5. Apathy was also observed while bees were previously hyperactive because hyperactivity is generally followed by tranquillity in chronic exposure (Suchail et al. 2001). 

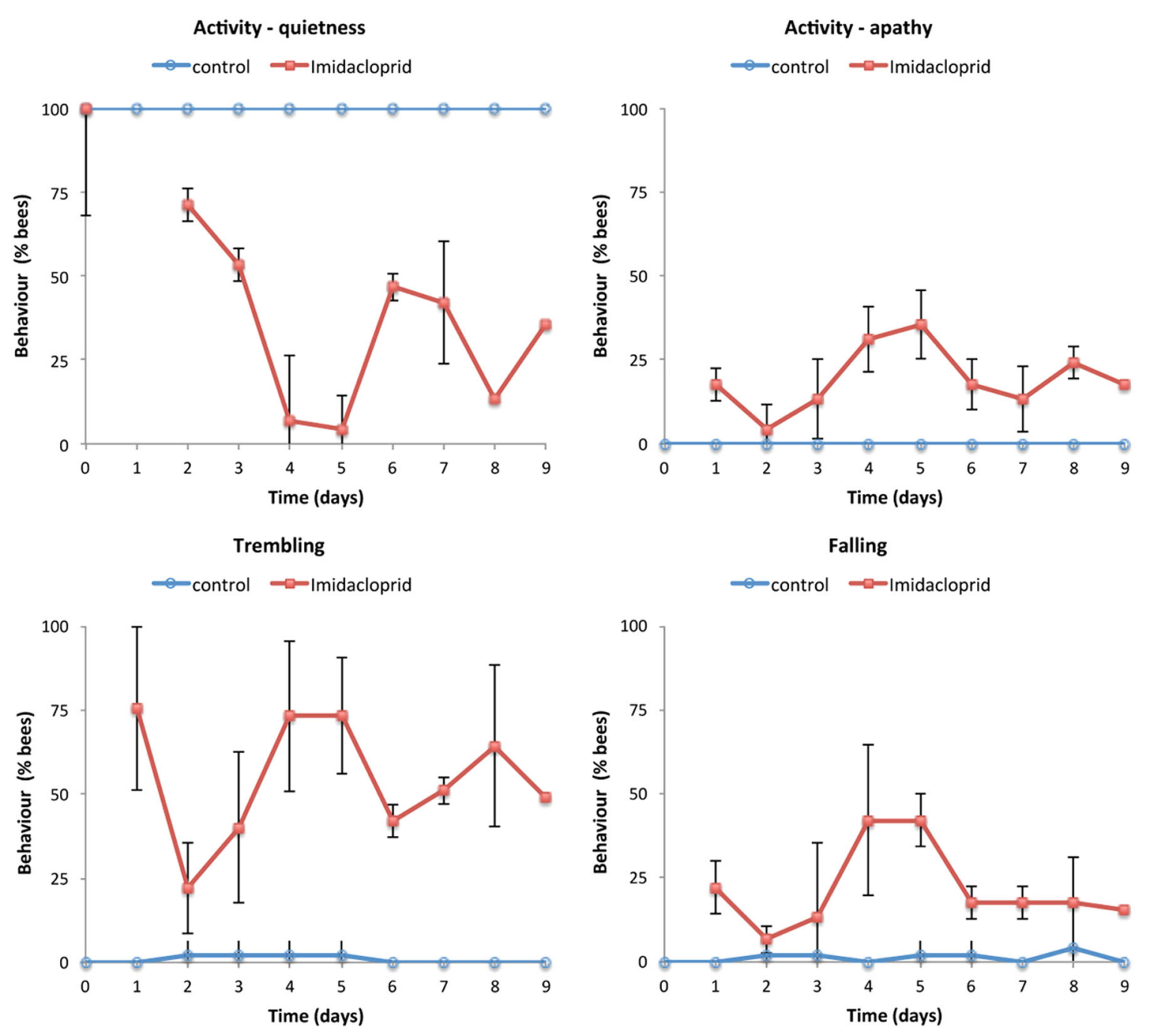

Fig. 3 Behavioural effects in honey bees chronically exposed to imidacloprid. Data points are percentage of honey bees (mean \pm SE) showing the corresponding behaviour from daily observations $(n=5)$ in nine cages. The behaviours of activity (quietness, apathy), trembling

The feeding activity was less frequent in exposed honey bees (average $3.7 \%$ bees) than in controls $(6.7 \%$ bees), although not statistically significant $(p=0.07$, paired $t$-test). No noticeable difference in general mobility (locomotion, $p=$ $0.21)$, trophallaxis $(p=0.73)$ and ventilation $(p=0.47)$ behaviours was observed between controls and imidaclopridexposed honey bees (data not shown).

\section{Discussion}

Our experiments were performed with winter honey bees, which are less sensitive to imidacloprid and other insecticides than the spring or summer honey bees (Decourtye et al. 2003; Meled et al. 1998) used by Cresswell et al. (2014). They also used smaller cages $\left(240 \mathrm{~cm}^{3}\right)$ than ours

and falling showed statistically significant differences $(p<0.05$, paired $t$-test) between control (circles) and treated bees (squares). In regard to activity, all non-quiet bees were hyperactive or restless

$\left(580 \mathrm{~cm}^{3}\right)$ under conditions of lower relative humidity (21-47\% compared to $70 \%$ in our case). However, these two technical variations are not expected to have any significant bearing on the toxicological effects and the metabolism of a potent insecticide like imidacloprid.

In our experiment, honey bees that fed on syrup con-

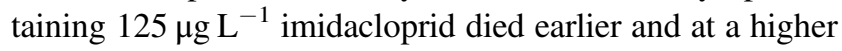
rate compared to bees that were fed untreated syrup (Fig. 1). After 2 days of exposure, the average corrected mortality rates in the treated cages were $38-46 \%$ (Fig. 1), whereas in the control cages mortality was 2 to $7 \%$. After 10 days, the mortality rate in the treatments was still about three times higher than in the controls for a total intake of $38.2 \mathrm{ng}$ imidacloprid per bee.

This exemplifies the strong effect of this concentration of imidacloprid on mortality even after a short exposure 
period: each bee had consumed in 2 days an average $11.4 \mathrm{ng}$ of imidacloprid (Fig. 2), an amount close to its 48-h oral LD50, which is typically in the range $30-60 \mathrm{ng}$ per bee (Blacquière et al. 2012), although some Bayer studies (Schmuck et al. 2001) have reported it as $4-41 \mathrm{ng}$ per bee. This is not surprising, since sensitivity towards neonicotinoids among honey bees from different genetic backgrounds can differ by a 33-fold factor (Rinkevich et al. 2015) or even more (Suchail et al. 2001).

According to a meta-analysis of toxicity data on imidacloprid for honey bees (Cresswell 2011), the total dose ingested by our bees in 2 days would have caused about $70 \%$ mortality (Fig. 1c in Cresswell 2011). Since winter bees are known to be less sensitive to toxicants than the newly eclosed bees usually tested, our results are consistent with the findings of that meta-analysis. Under similar conditions, Cresswell et al. (2014) reported a lower average consumption of $2.2 \mathrm{ng}$ of imidacloprid per day by their worker bees, which would have produced about $20-25 \%$ mortality in 2 days. Note that the total dosage of $17 \mathrm{ng}$ per bee in their 8-day experiment is about half the LD50 for honey bees.

We found bodily residues of imidacloprid parent compound in measureable amounts (2.7 to $\left.5.7 \mathrm{ng} \mathrm{g}^{-1}\right)$ throughout the entire exposure period (Fig. 2). The discrepancy between our results and the ones reported by Cresswell et al. (2014) may have different explanations. (i) Spring or summer bees, used by those authors, may present a higher metabolism than winter bees. This would result in a lower concentration of imidacloprid residues. However, this hypothesis is not supported by the lower sensitivity of winter bees that generally results from an increased metabolism and, in turn, a lower level of pesticide residues (Crailsheim 1986). (ii) In our study, 2 g samples were used (16-17 bees per sample at $0.12 \mathrm{~g}$ per honey bee). However, in the study of Cresswell et al., the starting sample mass was low, about $0.42 \mathrm{mg}$ of honey bees, and imidacloprid was extracted from a single bee $(0.14 \mathrm{~g}$ per bee) and then 3 extracts were pooled before analysis. Given the large variation in residue amounts usually found from bee to bee, smaller sample sizes can lead to greater variability of detections than larger samples. This agrees with the fact that using a higher sample mass of about $0.57 \mathrm{mg}$ for bumble bees, the same authors were able to detect and quantify imidacloprid. (iii) The recovery rates of the analytical method used by Cresswell et al. were only $64 \%$ for honey bees and $52 \%$ for bumble bees and were measured with internal standard added after extraction, not enabling the assessment of the actual recovery rate, which is necessarily lower. (iv) In Cresswell et al. (2014) imidacloprid concentrations in the syrup fed to the bees were nominal and not actual concentrations confirmed by analysis. Thus, a risk of under exposure cannot be completely ruled out.
The amount of imidacloprid residues in our bees declined with time (Fig. 2). This is probably due to a combination of the induction of detoxifying enzymes during daily chronic exposure and a reduction of the feeding behaviour (Yang et al. 2008). Syrup consumption rates in the cages with 30 bees were five times lower in the last day $(12 \pm 11 \mathrm{mg}$ per bee) than in the first day $(61 \pm 20 \mathrm{mg}$ per bee), explaining in part the slowdown in mortality observed after the first day (Fig. 1). The decline in body residues is also consistent with partial metabolism leading to the production of multiple metabolites, some of which are known to be toxic to honey bees (Suchail et al. 2004a; Suchail et al. 2001) and may account for some of the toxic effects observed. Contrasting with our observations, Cresswell et al. (2014) reported feeding rates that remained practically constant over time in newly eclosed summer honey bees (Fig. 2a in Cresswell et al. 2014).

It has been shown that, when honey bees are chronically exposed to $0.16 \mathrm{ng}$ per day of imidacloprid (i.e. an exposure 24 times lower than in our experiment or 14 times lower than that in Cresswell et al. (2014)), the toxic effects are still present and even increase after certain time, despite the fact that more than $90 \%$ of the parent compound is metabolised (Rondeau et al. 2014). Our data here show that $1-6 \%$ of imidacloprid parent compound remains in the bees, with its daily proportion increasing over time (Table 1). In spite of the rapid metabolism of this insecticide in honey bees, there was incomplete clearance of imidacloprid in our honey bees and residues of this neurotoxicant remained above the quantifying level in the bees' bodies, which is consistent with the lethal and behavioural effects observed. More generally, there is no evidence of unusually high metabolism in this species of bees. On the contrary, honey bees seem to exhibit a deficit of detoxification mechanisms (Claudianos et al. 2006) that makes them as sensitive to pesticides as bumble bees by either oral or contact exposure (Arena and Sgolastra 2014; Marletto et al. 2003; Thompson 2016) or even more sensitive (Hardstone and Scott 2010; Sánchez-Bayo and Goka 2014). As a matter of fact, our winter honey bees displayed symptoms of intoxication similar to those exhibited by the bumble bees in Cresswell et al. (2014).

In our experiment, intoxicated honey bees moved only slightly less than the control bees, with no statistical difference among them (locomotion, $p=0.21$ ). Our results suggest that trembling, restlessness, apathy and falling over may be more sensitive endpoints than walking for assessing sublethal effects of imidacloprid in honey bees (Fig. 3). Indeed, the locomotor activity (walking) in cages, may not be suitable for studying sublethal toxic effects in bees, as other authors have shown that $100 \mu \mathrm{g} \mathrm{L}^{-1}$ of imidacloprid in syrup caused significant motion impairment in honey 
bees only within the first $3 \mathrm{~h}$, but not afterwards (Medrzycki et al. 2003).

Cresswell et al. (2014) reported that worker honey bees neither experienced any adverse effects (lethal or locomotion) nor present residues in their bodies after feeding during 8 days on syrup containing a biological active concentration of imidacloprid $\left(125 \mu_{\mathrm{g} \mathrm{L}}^{-1}\right)$. We could not reproduce their findings using winter bees and the same methods used by those authors. Any lack of residues and effects strongly suggest under exposure. It can be assumed that the spring or summer bees they used would exhibit similar or more pronounced effects than winter bees because of their higher sensitivity to pesticides, but, as already indicated, decreased sensitivity to toxicants typically involves a higher detoxifying metabolism (Crailsheim 1986). Hence, bodily residues are expected to be lower in winter bees than in summer bees. The absence of residues in summer bees contrasts with reports by other authors (Bacandritsos et al. 2010; Bortolotti et al. 2009; CalatayudVernich et al. 2016; Dively et al. 2015; Hladik et al. 2016), who have shown that residues of imidacloprid can be quantified in summer honey bees exposed to environmental levels of this insecticide, which are typically lower than those tried in this study and in that of Cresswell et al. (2014).

\section{Conclusions}

We reproduced the experiments of Cresswell et al. (2014) using winter honey bees and our results differ completely from those reported by those authors. We found that imidacloprid parent compound is present in honey bees at measureable levels when they are fed syrup contaminated with this insecticide at $125 \mu \mathrm{g} \mathrm{L}^{-1}$. The presence of imidacloprid in honey bees was revealed right from the beginning of the exposure and remained measurable during 10 days. The parent imidacloprid residues decreased slightly and progressively, with an apparent half-life of 7.6 days, which is about 36 times longer than the half-life estimated after a single exposure (Suchail et al. 2004a; Suchail et al. 2004b). Therefore, there was not a $100 \%$ clearance of imidacloprid in winter honey bees. Furthermore, when comparing the residues of imidacloprid with its daily intake, we observed an increase of the relative amount of the chemical in the bees, which suggest an adverse effect on their detoxification ability.

Chronic exposure of winter honey bees to imidacloprid did not induced a significant change in mobility (locomotion), as reported also by Cresswell et al. (2014) for spring or summer honey bees. However, such an exposure induced a strong lethal effect on the second day (38-46\% mortality) and mortality remained three times higher than that of the controls during the 10 days of our experiment. This level of exposure also induced typical sublethal effects on honey bees (restless, trembling, apathetic and falling over) that were statistically significant $(p<0.05)$, whereas the decrease in the feeding activity was found less significant. Therefore, both lethal and sublethal effects of imidacloprid were observed in winter honey bees.

Further experiments, considering several levels of exposure with spring, summer and winter honey bees, could be very useful to better understand the effects of imidacloprid or other neonicotinoids, as well as their metabolism in honey bees.

Funding This study was only supported by the recurrent funding of the respective research organisms of the authors.

\section{Compliance with ethical standards}

Conflict of interest The authors declare that they have no competing interests.

Ethical approval All applicable international, national, and/or institutional guidelines for the care and use of animals were followed.

\section{References}

Alkassab AT, Kirchner WH (2016) Impacts of chronic sublethal exposure to clothianidin on winter honeybees. Ecotoxicology 25 (5): 1000-1010

Arena M, Sgolastra F (2014) A meta-analysis comparing the sensitivity of bees to pesticides. Ecotoxicology 23(3):324-334

Bacandritsos N, Granato A, Budge G, Papanastasiou I, Roinioti E, Caldon M, Falcaro C, Gallina A, Mutinelli F (2010) Sudden deaths and colony population decline in Greek honey bee colonies. J Invertebr Pathol 105(3):335-340

Blacquière T, Smagghe G, van Gestel C, Mommaerts V (2012) Neonicotinoids in bees: a review on concentrations, side-effects and risk assessment. Ecotoxicology 21(4):973-992

Bonmatin JM, Moineau I, Charvet R, Fleche C, Colin ME, Bengsch ER (2003) A LC/APCI-MS/MS method for analysis of imidacloprid in soils, in plants, and in pollens. Anal Chem 75 (9):2027-2033

Bortolotti L, Sabatini AG, Mutinelli F, Astuti M, Lavazza A, Piro R, Tesoriero D, Medrzycki P, Sgolastra F, Porrini C (2009) Spring honey bee losses in Italy. Julius-Kuhn-Archiv 423:148-152

Calatayud-Vernich P, Calatayud F, Simó E, Suarez-Varela MM, Picó $\mathrm{Y}$ (2016) Influence of pesticide use in fruit orchards during blooming on honeybee mortality in 4 experimental apiaries. Sci Total Environ 541:33-41

Claudianos C, Ranson H, Johnson RM, Biswas S, Schuler MA, Berenbaum MR, Feyereisen R, Oakeshott JG (2006) A deficit of detoxification enzymes: pesticide sensitivity and environmental response in the honeybee. Insect Mol Biol 15(5):615-636

Colin ME, Bonmatin JM, Moineau I, Gaimon C, Brun S, Vermandere JP (2004) A method to quantify and analyze the foraging activity of honey bees: relevance to the sublethal effects induced by systemic insecticides. Arch Environ Contam Toxicol 47 (3):387-395 
Crailsheim K (1986) Dependence of protein metabolism on age and season in the honeybee (Apis mellifica carnica Pollm). J Insect Physiol 32(7):629-634

Cresswell J (2011) A meta-analysis of experiments testing the effects of a neonicotinoid insecticide (imidacloprid) on honey bees. Ecotoxicology 20(1):149-157

Cresswell JE, Page CJ, Uygun MB, Holmbergh M, Li Y, Wheeler JG, Laycock I, Pook CJ, de Ibarra NH, Smirnoff N et al. (2012) Differential sensitivity of honey bees and bumble bees to a dietary insecticide (imidacloprid). Zoology 115(6):365-371

Cresswell JE, Robert F-XL, Florance H, Smirnoff N (2014) Clearance of ingested neonicotinoid pesticide (imidacloprid) in honey bees (Apis mellifera) and bumblebees (Bombus terrestris). Pest Manag Sci 70(2):332-337

Decourtye A, Lacassie E, Pham-Delègue M-H (2003) Learning performances of honeybees (Apis mellifera L) are differentially affected by imidacloprid according to the season. Pest Manag Sci 59(3):269-278

Desneux N, Decourtye A, Delpuech J-M (2007) The sublethal effects of pesticides on beneficial arthropods. Annu Rev Entomol 52:81-106

Dively GP, Embrey MS, Kamel A, Hawthorne DJ, Pettis JS (2015) Assessment of chronic sublethal effects of imidacloprid on honey bee colony health. PLoS One 10(3):e0118748

Hardstone MC, Scott JG (2010) Is Apis mellifera more sensitive to insecticides than other insects? Pest Manag Sci 66 (11):1171-1180

Hladik ML, Vandever M, Smalling KL (2016) Exposure of native bees foraging in an agricultural landscape to current-use pesticides. Sci Total Environ 542:469-477

Laycock I, Lenthall K, Barratt A, Cresswell J (2012) Effects of imidacloprid, a neonicotinoid pesticide, on reproduction in worker bumble bees (Bombus terrestris). Ecotoxicology 21 (7):1937-1945

Marletto F, Patetta A, Manino A (2003) Laboratory assessment of pesticide toxicity to bumble bees. Bull Insectol 56(1):155-158

Medrzycki P, Montanari R, Bortolotti L, Sabatini AG, Maini S, Porrini C (2003) Effects of imidacloprid administered in sublethal doses on honey bee behaviour. Laboratory tests. Bull Insectol 56 (1):59-62

Meled M, Thrasyvoulou A, Belzunces LP (1998) Seasonal variations in susceptibility of Apis mellifera to the synergistic action of prochloraz and deltamethrin. Environ Toxicol Chem 17 (12):2517-2520

Moffat C, Buckland ST, Samson AJ, McArthur R, Chamosa Pino V, Bollan KA, Huang JTJ, Connolly CN (2016) Neonicotinoids target distinct nicotinic acetylcholine receptors and neurons, leading to differential risks to bumblebees. Sci. Rep 6:24764

Ramirez-Romero R, Chaufaux J, Pham-Delègue M-H (2005) Effects of Cry1 Ab protoxin, deltamethrin and imidacloprid on the foraging activity and the learning performances of the honeybee Apis mellifera, a comparative approach. Apidologie 36(4):601-611

Rinkevich FD, Margotta JW, Pittman JM, Danka RG, Tarver MR, Ottea JA, Healy KB (2015) Genetics, synergists, and age affect insecticide sensitivity of the honey bee, Apis mellifera. PLoS One 10(10): 0139841

Rondeau G, Sánchez-Bayo F, Tennekes HA, Decourtye A, RamírezRomero R, Desneux N (2014) Delayed and time-cumulative toxicity of imidacloprid in bees, ants and termites. Sci Rep 4:5566

Sánchez-Bayo F, Goka K (2014) Pesticide residues and bees-a risk assessment. PLoS One 9(4):e94482

Schmuck R, Schöning R, Stork A, Schramel O (2001) Risk posed to honeybees (Apis mellifera L, Hymenoptera) by an imidacloprid seed dressing of sunflowers. Pest Manag Sci 57(3):225-238

Suchail S, Debrauwer L, Belzunces LP (2004a) Metabolism of imidacloprid in Apis mellifera. Pest Manag Sci 60(3):291-296

Suchail S, Guez D, Belzunces LP (2001) Discrepancy between acute and chronic toxicity induced by imidacloprid and its metabolites in Apis mellifera. Environ Toxicol Chem 20(11):2482-2486

Suchail S, de Sousa G, Rahmani R, Belzunces LP (2004b) In vivo distribution and metabolisation of 14C-imidacloprid in different compartments of Apis mellifera L. Pest Manag Sci 60 (11):1056-1062

Teeters BS, Johnson RM, Ellis MD, Siegfried BD (2012) Using videotracking to assess sublethal effects of pesticides on honey bees (Apis mellifera L.). Environ Toxicol Chem 31(6):1349-1354

Thompson H (2016) Extrapolation of acute toxicity across bee species. Integr Environ Assess Manag 12(4):622-626

Thompson HM (2001) Assessing the exposure and toxicity of pesticides to bumblebees (Bombus sp.). Apidologie 32:305-321

Thompson HM, Wilkins S, Harkin S, Milner S, Walters KFA (2015) Neonicotinoids and bumblebees (Bombus terrestris): effects on nectar consumption in individual workers. Pest Manag Sci 71 (7):946-950

Williamson SM, Willis SJ, Wright GA (2014) Exposure to neonicotinoids influences the motor function of adult worker honeybees. Ecotoxicology 23(8):1409-1418

Yang EC, Chuang YC, Chen YL, Chang LH (2008) Abnormal foraging behavior induced by sublethal dosage of imidacloprid in the honey bee (Hymenoptera: Apidae). J Econ Entomol 101 (6): 1743-1748 